\title{
Assessing the Condition of Gas Turbine Rotor Blades with the Optoelectronic and Thermographic Methods
}

\author{
Mariusz Bogdan ${ }^{1, *}$, Józef Błachnio ${ }^{2}$, Artur Kułaszka ${ }^{2}$ and Marcin Derlatka ${ }^{1}$ \\ 1 Department of Mechanical Engineering, Bialystok Technical University, 45 Wiejska str., 15-333 Białystok, \\ Poland; m.derlatka@pb.edu.pl \\ 2 Air Force Institute of Technology, 6 Księcia Bolesława str., 01-494 Warszawa, Poland; \\ jozef.blachnio@itwl.pl (J.B.); artur.kulaszka@itwl.pl (A.K.) \\ * Correspondence: m.bogdan@pb.edu.pl; Tel.: +48-571443043
}

Received: 30 November 2018; Accepted: 22 December 2018; Published: 2 January 2019

\begin{abstract}
Gas turbines and their blades in particular might be damaged in the course of the aviation turbojet engine operation process. The degradation process of the blade microstructure is most evident from the change in the colour of its surface. This is assessed using the optoelectronic method. The article presents the concept of non-destructive methods, which are used to assess the degree of degradation of the alloy of a gas turbine blade. The proposed optoelectronic method is the basic method for the preliminary determination of color changes in the surface. Appropriate videoscopes or video-analyzers, capable of recording a test object in various electromagnetic wave ranges (infrared radiation, visible range), are used for this purpose. These preliminary results of the diagnosis make it possible to infer further studies of the blade. For accurate investigation of the state of the alloy microstructure, a non-destructive thermographic method (xenon flash pulsed thermography) was used. The results of studies of the degradation of the microstructure with the use of non-destructive methods were verified through the use of metallographic investigations. Appropriate metallographic specimens were created in order to recognize phase $\gamma^{\prime}$ degradation (i.e., the phase strengthening the blade alloy). The results of the presented research allowed for an in-depth assessment of the degree of microstructure degradation of operated blades.
\end{abstract}

Keywords: Turbine blade; digital image; impulse thermography; microstructure degradation

\section{Introduction}

The technical condition of turbine blades in the operating process of aviation turbojet engines is of decisive importance for the reliability and durability of a turbine and the entire engine [1,2]. The main reason gas turbine blades get damaged is overheating of their material as well as thermal fatigue [3-5]. This is caused by adverse operating conditions or manufacturing defects. Important factors causing turbine blade damage are: Insufficiently strong superalloys and protective coatings applied to the blade (vanes), and the use of fuel with decreased quality requirements. The most important factors are complex conditions of mechanical and thermal loads in the course of turbine operation. Exceeding the permissible flue gas temperature, especially over a long operation period, as well as disturbances in or lack of sufficient cooling of turbine blades are particularly dangerous.

The evaluation of the technical deterioration of operated blades with non-destructive methods enables, in certain cases, the extension of the service life of an engine even after detection of a permissible defect or to decommission an engine before catastrophic turbine damage appears. The optoelectronic method is the most common method in the process of diagnosing a technical condition of turbine elements [6-8]. Through the use of a videoscope or a video-analyser, it enables 
non-invasive testing of even hard to reach engine elements and to assess its condition by comparing the obtained image of a tested blade surface with a reference image (Figure 1).

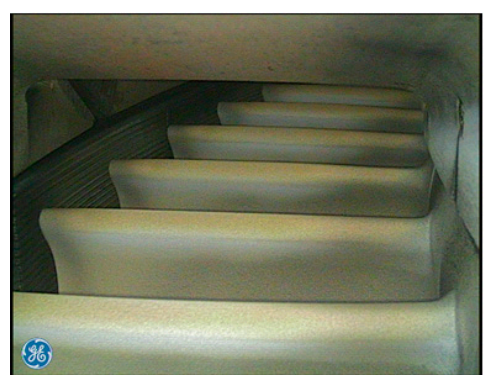

(a)

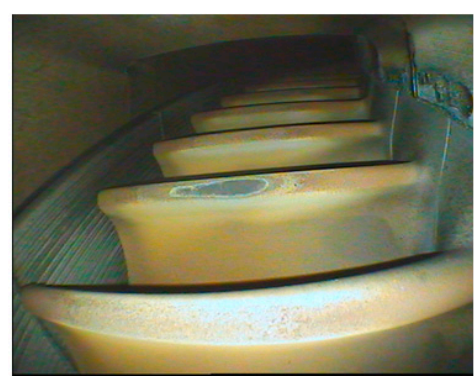

(b)

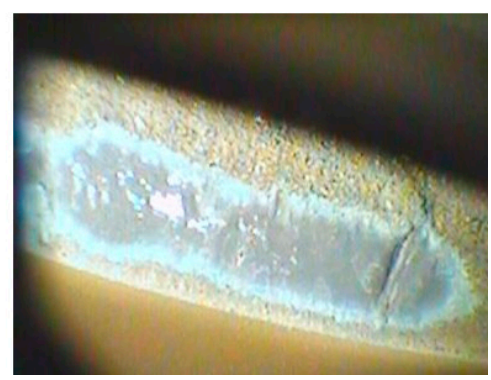

(c)

Figure 1. Results of a turbine rotor blade edge of an attack technical condition test using the optoelectronic method: (a) Reference image; (b) overheating manifested by a colour change; (c) overheating and fatigue cracking.

A gas turbine blade destruction process usually starts on the edge of attack in the form of overheating or cracking [9]. The blade material is exposed to direct, aggressive impact of flue gases, which leads to adverse microstructural changes [10-12], putting the blade out of operation (use). An illuminated blade surface may be viewed with a light-sensitive detector thanks to a secondary light source reflected off its surface. As a result, a direct diagnostics method for a tested object is possible, involving the processing and analysis of obtained data in the form of digital images (visible range) $[13,14]$. Some of the new, intensively developing, non-destructive diagnostic tests in the field of infrared radiation which deserve attention include non-destructive thermographic methods [15-18].

Subsequent chapters of the paper present the execution stages of the tests. Considering the short description of the object, tests, and experimental conditions in the second chapter, the justification of the adopted methodology and issue analysis was briefly explained. Chapter 3 presents test results regarding soaked, as well as operated blades tested using two methods: The optoelectronic method and the thermographic method. Section 3.3 contains the validation of the suggested approach through non-destructive testing on microsections (metallographic test). Section 3.4 attempts to briefly include the conclusions regarding the previously presented results.

\section{Materials and Methods}

This chapter pays particular attention to the description of the test object mainly in the scope of its microstructure and parameters, which are of decisive influence on its strength properties-heat resistance and creep resistance of the superalloy. A description of these test methods, justification for their application, and the conditions of the conducted tests were also presented.

\subsection{Characteristics of the Object and Description of Material Tests}

The tests covered blades of an aviation turbojet engine gas turbine. Blades in the engine are not cooled. They are made of a nickel superalloy called EI-867 WD (HN62MWKJu), for plastic treatment (Table 1).

Table 1. Chemical composition of alloy EI-867 WD [\%].

\begin{tabular}{cccccccccccc}
\hline $\mathbf{C}$ & Mo & Si & Cr & Ni & Co & Mo & W & Al & B & Fe & Other \\
\hline $\max$ & $\max$ & $\max$ & & rest & 14 & 10.3 & 5.0 & 4.5 & 0.02 & 4.0 & $0.3 \mathrm{~V}, 01 \mathrm{Ba} \max$ \\
0.1 & 0.3 & 0.6 & 9.0 & & 14 &
\end{tabular}

The structure of the EI-867 WD alloy is typical for nickel superalloys and consists of: A matrix, composed of phases $\gamma$, alloy reinforcing phase $\gamma^{\prime}$ as well as carbides and borides. Particles of the 
$\gamma^{\prime}$ phase $\left(\mathrm{Ni}_{3} \mathrm{Al}\right)$ are cubical. The relative volume of phase $\gamma^{\prime}$ after standard alloy heat treatment is $31 \div 34 \%$. Heat treatment includes supersaturation and ageing. Air cooling during supersaturation already leads to the precipitation of fine particles of the $\gamma^{\prime}$ phase with their relative volume being approximately $20 \%$. Ageing causes further precipitates of particles in the phase $\gamma^{\prime}$ and expansion of previously precipitated particles. The relative volume of carbides in the alloy does not exceed $2 \%$, with carbide $\mathrm{M}_{23} \mathrm{C}_{6}$ dominating. It is formed during heat treatment or is precipitated during operation, usually at grain boundaries, within a temperature range of $933 \mathrm{~K}-1253 \mathrm{~K}$. The $\mathrm{M}_{6} \mathrm{C}$ carbide appears inside the grains $[19,20]$. New (heated) as well as operated (removed from an actual turbine-object, characterized by varying technical condition) blades were used as research material. The values of established heating temperatures of new blades are associated with the range of temperatures present during normal and emergency operation of rotor blades. The average temperature of the working agent (flue gas) at the aviation turbojet combustion chamber outlet, due to limitations resulting from thermal and chemical alloy properties, should not exceed $1200 \mathrm{~K}$ [21]. Therefore, new blades heated in an oven for $2 \mathrm{~h}$ in the presence of aviation kerosene flue gases at different temperatures were used for the tests. The applied temperatures corresponded to: Turbine operation, critical temperature, and supercritical temperatures relative to the turbine operation temperature, i.e., in the range from $1123 \mathrm{~K}$ to $1523 \mathrm{~K}$.

Metallographic tests on microsections were conducted in order to verify the technical condition of the blades with a non-destructive method. The microstructure of the alloy subject to high temperature was analysed (laboratory conditions, actual conditions), providing detailed information regarding microstructural changes. In order to determine the technical condition of the studied objects, a material criterion was used, i.e., modification of the size and distribution of the dispersive $\gamma^{\prime}$ phase and the alloy grain size (Nikon Eclipse MA200, Tokyo, Japan, scanning microscope with its software NIS-Elements AR/BR v. 3.0, made by Nikon, Tokyo, Japan). The reinforcing phase $\gamma^{\prime}$ significantly impacts the strength properties (including susceptibility to brittle fracture) of an alloy [22-24].

\subsection{Characteristics of the Optoelectronic Method}

An illuminated blade surface may be recognized by a light-sensitive detector Charge-Coupled Device $(C C D)$ matrix with an optic system = optoelectronic system) thanks to a secondary light source reflected off its surface. As a result, an indirect diagnostics method for a tested object is possible, involving the processing and analysis of obtained data. A light flux falling on a metal surface is absorbed to a very small extent. The majority (90\%-95\%) of the light is re-emitted from the surface in the form of visible light with the same wave length as incident light. The remaining $5 \%-10 \%$ of the energy is dispersed in the form of heat (according to the energy conservation principle) [24]. The chemical structure of the matter covering the surface of metal objects determines the damping of individual wavelengths within the radiation spectrum illuminating a given object, and the mixture of light selectively reflected from a given surface determines its colour.

Blade surface images in the range of visible light were recorded at the research station (Figure 2). High repeatability of the measurements was ensured through setting fixed acquisition conditions, the selection of an appropriate light source, and the uniform illumination of photographed surfaces as well as prevention of halos and geometric deformations, etc. The blades were arranged on a mat surface in groups of several units, ensuring that blade sets were recorded in identical conditions, thus making it possible to determine the differences between the surface colours of blades in various technical conditions. 


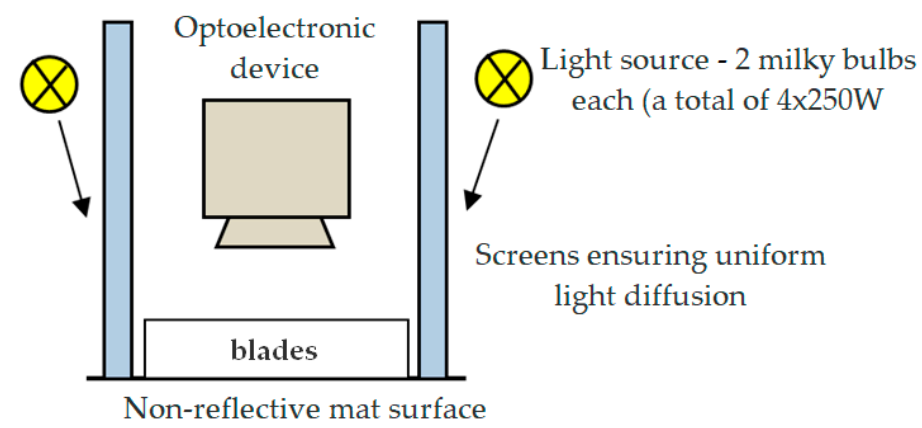

Figure 2. Acquisition position for images of tested blade surfaces.

The colour of individual blades is an important feature describing their condition. Moreover, from the point of view of determining the values of diagnostic parameters, the colour surface of blades may constitute a source for enabling the extraction of information independently from image scaling, translation, and rotation (extracting colour properties through selecting an appropriate colour space combined with a quantitative description of the colour). That is the reason the first test stage involved searching for the appropriate representation of image data, which would explicitly reflect the differences in blade surface colours and, within the first phase, it was decided to track the possibilities of extracting surface colour properties from different representations of image data included in various colour models, i.e., RGB, HSV, YCbCr, L*a*b (CIE $1976 \mathrm{~L}^{*} \mathrm{a}^{*} \mathrm{~b}^{*}$ ) [24,25]. Colour descriptors utilizing individual components of various colour models, i.e., RGB, HSV, YCbCr, $\mathrm{L}^{*} \mathrm{a}^{*} \mathrm{~b}^{*}$, for blades in different technical conditions were used for the assessment (description) of surface blade colour properties. The following parameters were considered [26-29]:

- Colour moments: General surface properties defined by basic values, such as the average value, standard deviation, and variance;

- colour histogram parameters: The characteristics of parameters describing the histograms for individual colour components in an adopted colour model. A histogram is an effective and concise representation of the visual content of a digital image. Its advantages include determination simplicity, resistance to translation and rotation of the view axis, limited sensitivity to scale changes, and a changing image view angle. However, a histogram does not include information about the spatial structure of an image; and

- colour coherence vector (CCV): Is an expansion of the histogram concept with spatial information. A given colour (histogram bar, colour component) is classified as coherent or incoherent, depending on whether the pixels representing it form a coherent, closed area in an image or are dispersed. The coherence vector is in the form of: $\{(\mathrm{a} 1, \mathrm{~b} 1),(\mathrm{a} 2, \mathrm{~b} 2), \ldots,(\mathrm{aN}, \mathrm{bN})\}$, where $\mathrm{a}_{\mathrm{i}}$ means the number of pixels forming a coherent area and bi the number of pixels in non-coherent areas.

\subsection{Characteristics of the Thermographic Method}

The essence of infrared thermography is a measurement covering detection, recording, processing, and visualisation of an invisible electromagnetic radiation emitted by every solid body and having a temperature higher than absolute zero. The end result of the measurement is image data (thermograms), which reflects the temperature distribution over the surface of the tested object [17,30-32]. Various infrared thermography methods and techniques are used in non-destructive material tests. They have specific advantages, but also limitations, resulting from the physical characteristics of the applied phenomena, structure of the tested objects as well as the measuring equipment being used. Nevertheless, generally, the radiation power of a body depends on its temperature, uniformity of its structure as well as the temperature of the environment, while heat flow is contingent on the conductivity, thermal capacity, and diffusivity of a given material. On the basis of the obtained results of thermographic tests related to a reference value, we can, therefore, infer about material property changes (alloy microstructure) under the influence of adverse operating factors, 
such as prolonged operation at an elevated temperature [17,31]. Such an approach, given the material criterion, enables a diagnostic assessment of a blade's technical condition and its fitness for further use.

The execution of non-destructive tests with the use of infrared thermography applies to the procedures of passive and active tests [30-32]. Passive approaches are mainly applied for testing devices or their elements during operation or shortly after its completion (no interference in the heat exchange processes between the object and the environment), when the difference in surface temperature distribution can denote their defectiveness. In contrast to passive thermography, active thermography requires the use of external thermal excitation, which, through heat exchange processes (conduction, convection, or radiation), will induce heat wave propagation inside as well as on the surface of a tested object. An external thermal stimulation source (heating or cooling) may concern the entire tested object or its part. Thermal response from an object enables the recording of dynamic temperature fields, with test results being significantly dependent on the observation time [30]. Depending on the manner of thermal stimulation as well as the processing and analysis of thermographic data in applications associated with aviation we can distinguish [33,34]: Pulsed thermography (PT), lock-in thermography (LIT), step heating thermography (SHT), long pulse thermography (LPT), frequency modulated thermography (FMT), laser-spot thermography (LST), and laser-line thermography (LLT).

Most works are associated with the use of active thermography for detecting material defects, also in a composite material (identifying their presence or lack of in the matrix material), in the subsurface layer and attempts to evaluate their magnitude and estimate the location (depth) of such defects for various types of material, including the ones used in aviation [32]. Some papers are devoted to the issue of the detection of cracks appearing on the blade's (vane) surface $[35,36]$. The method of pulsed thermography with appropriately prepared software was used, among others, in papers aimed at determining its suitability for assessing the flow capacity of internal cooling channels of blades (blades are examined using a traditional optical method, the RAW and thermographic signal reconstruction used in a thermographic device) [37,38]. Its advantage over the radiographic method is that it does not require the application of radiation harmful to the verifier, and hence special test rooms, and results in a lower test cost. The described, in the literature $[18,31,37,38]$, pulsed thermography test results of objects conducted with the purpose to detect material non-linearity became an inspiration to commence work aimed at determining the possibility to apply this method for evaluating microstructural changes in gas turbine blades. Based on the location of thermal stimulation sources and an infrared camera located on the same side, the approach towards non-invasive assessment of turbojet engine blades technical condition proposed by the authors is classed as a reflection method-Figure 3. In the case shown in Figure 3, this involves short-term heating of the blade surface with a heat pulse (heating time lasting a few milliseconds). This way, a certain amount of energy is delivered to the material surface, which, after damping of the temperature, will rapidly change. Thanks to thermal diffusion, the thermal front will move to the inside of the material. The presence of areas standing out due to their thermo-physical properties induces a change in the diffusion speed. When monitoring a temperature field on the surface of cooling samples, it is possible to analyse not only the non-linearities present in the material, but also adverse mictrostructural changes of the tested material [31,39]. 


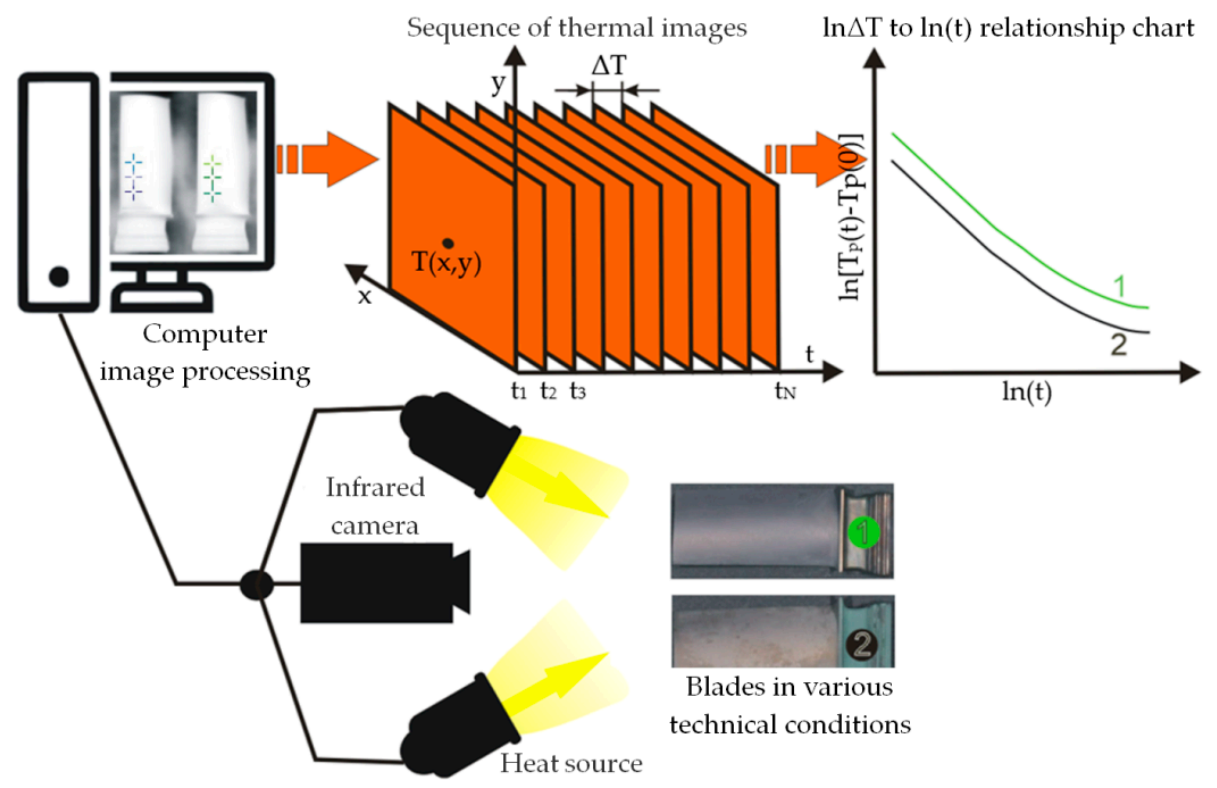

Figure 3. Pulsed thermography application diagram.

Thermal diffusivity, $a$, is the basic physical quantity necessary to determine a variable over time fields and temperature gradients. It is directly connected to a very important thermophysical parameter, thermal conductivity, $\lambda$. It should be noted, however, that the thermal conductivity characterizes the material as a conductor under conditions of steady-state heat exchange while thermal diffusivity is a criterion for a given material under conditions of unsteady-state heat exchange. Thermal diffusivity of static, isotropic, and non-transparent solids with thermal diffusivity density, $\rho$, fixed heat under constant pressure, $C_{p}$, and efficiency of internal heat sources, $q_{v}$, is usually a function with values largely dependent on temperature, $T(x, y, z, t)$, whose space-time distribution is determined by the Fourier-Kirchhoff equation [40]. In the Cartesian coordinate system, it takes the form:

$$
\frac{\partial T}{\partial t}=a \nabla^{2} T+\frac{1}{\rho C_{p}} \frac{\partial \lambda}{\partial T}\left[\left(\frac{\partial T}{\partial x}\right)^{2}+\left(\frac{\partial T}{\partial y}\right)^{2}+\left(\frac{\partial T}{\partial z}\right)^{2}\right]+\frac{q_{v}}{\rho C_{p}},
$$

Thermal diffusivity, a, as a measure of the ability of a given medium to conduct heat (namely, its thermal conductivity) and its ability to store heat (namely, thermal capacity) is expressed by the formula:

$$
a=\frac{\lambda}{\rho C_{p}}
$$

Therefore, the bigger the value of material heat diffusivity, the faster the phenomenon of temperature equalization over time proceeds.

\section{Results and Discussion}

This chapter presents the test results regarding the optoelectronic and thermographic method for heated as well as operated blades. The obtained results were juxtaposed with metallographic tests, which are a source of information about microstructural superalloy changes induced by the impact of various temperature values (heating in laboratory conditions, operated blades-operating conditions). This was supported with conclusions included in Section 3.4.

\subsection{The Optoelectronic Method and Test Results}

The blade oven heating process in the presence of aviation kerosene lasted for $2 \mathrm{~h}$. Next, the blades were allowed to cool in the oven. After cooling, blade surface images, shown in Figure 2, were recorded. 
It has been concluded that in the range of visible light, there was a colour change of their surface dependant on the heating temperature of individual blades (Figure 4).

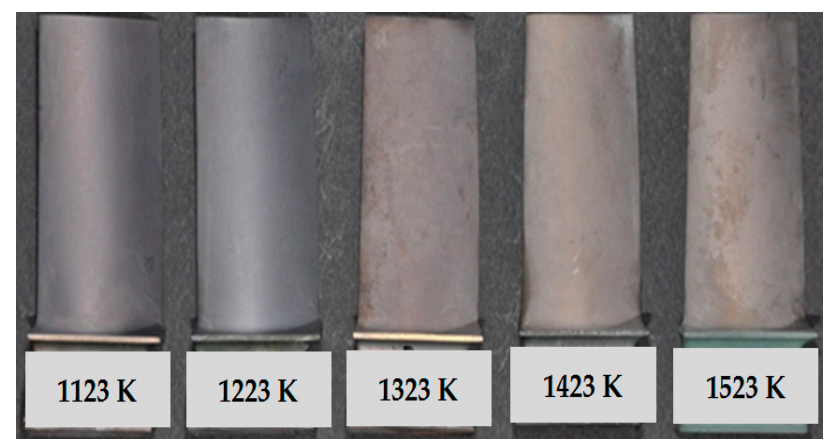

Figure 4. The surface image of blades heated in an oven for $2 \mathrm{~h}$ at temperatures ranging from $1123 \mathrm{~K}$ to $1523 \mathrm{~K}$ in the presence of aviation kerosene.

Figure 5 shows the spatial distribution of image points (pixels) for two surfaces of blades heated at $1123 \mathrm{~K}$ and $1523 \mathrm{~K}$ for different colour models, i.e., RGB, HSV, YcbCr, $\mathrm{L}^{*} \mathrm{a}^{*} \mathrm{~b}^{*}$. The apparent visible differences result from the representation of image data as well as were associated with various surface colours.

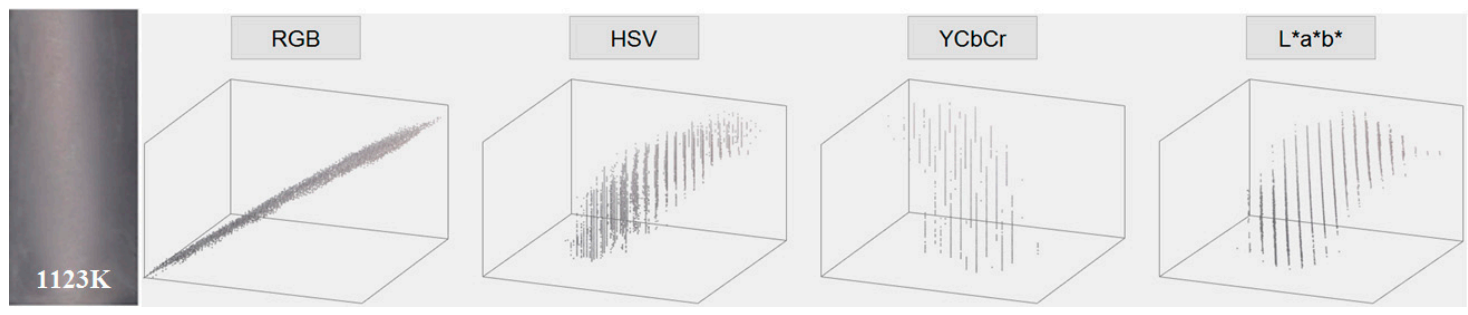

(a)

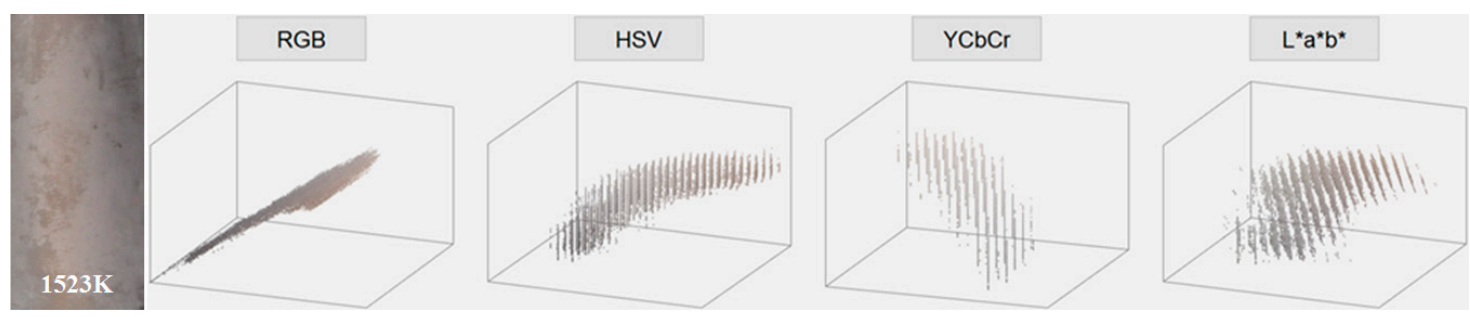

(b)

Figure 5. The differences in the colour representation of two exemplary surfaces in spatial models (image points-pixels): (a) $1123 \mathrm{~K}$; (b) $1523 \mathrm{~K}$.

Based on the differences (discriminant features) determined based on the colour moments, histogram parameters, and the coherent vector, the $\mathrm{L}^{*} \mathrm{a}^{*} \mathrm{~b}^{*}$ colour space model was chosen (colour model spreading between opposite colours forming the following dimensions: Dimension, $\mathrm{L}^{*}$, meaning brightness, and dimensions, $\mathrm{a}^{*}$ and $\mathrm{b}^{*}$, based on non-linearly compressed coordinates of the colour space, CIEXYZ). The $\mathrm{L}^{*} \mathrm{a}^{*} \mathrm{~b}^{*}$ model, despite the fact that through its use it is impossible to fully uniformly distribute colour in space, is currently the most popular colour description manner, allowing colour identification to be more independent from the class of a recording device (e.g., camera or spectrometer). The colour analysis results were presented in the $L^{*} a^{*} b^{*}$ colour space for only these blades where significant changes relating to their surface colour were recorded. Individual component images, $L^{*}, a^{*}, b^{*}$, are shown in Figure 6. 


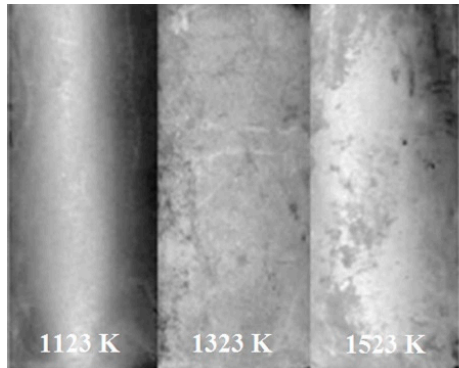

(a)

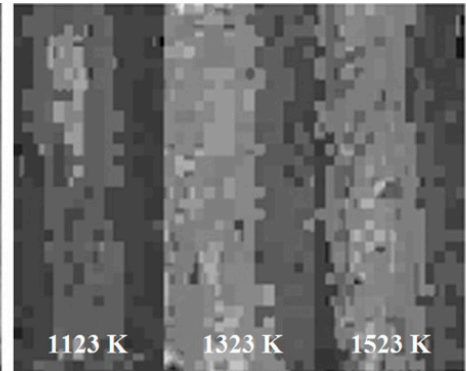

(b)

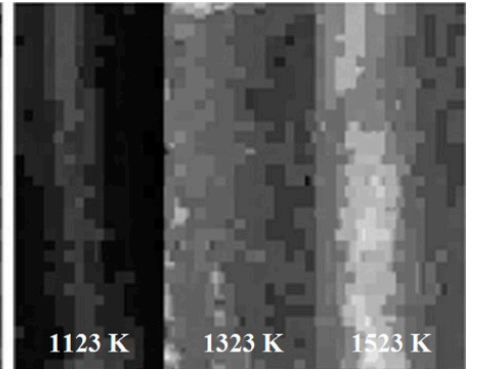

(c)

Figure 6. An exemplary representation of blade surfaces heated at three temperatures, i.e., $1123 \mathrm{~K}, 1323$ $\mathrm{K}$, and $1523 \mathrm{~K}$, for individual components in the $\mathrm{L}^{*} \mathrm{a}^{*} \mathrm{~b}^{*}$ model; component: (a) $\mathrm{L}^{*}$; (b) $\mathrm{a}^{*}$; (c) $\mathrm{b}^{*}$.

Figure 7 shows histograms determined on the basis of surface images (Figure 6) for components, $\mathrm{L}^{*}, \mathrm{a}^{*}$, and $\mathrm{b}^{*}$, for various blade heating temperatures. The results presented in Figure 7 depict the varied distribution of individual component values for each blade surface image point.

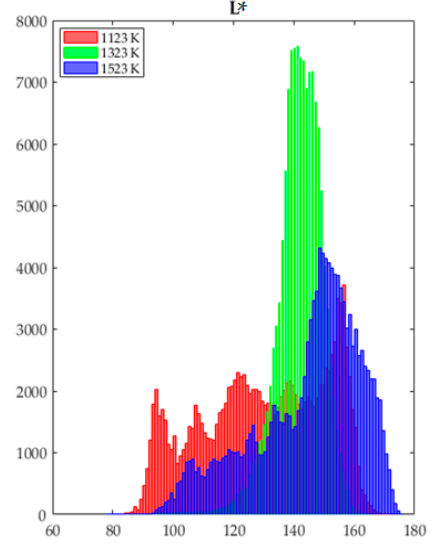

(a)

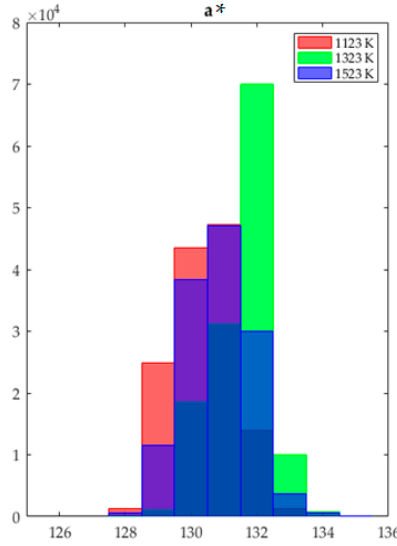

(b)

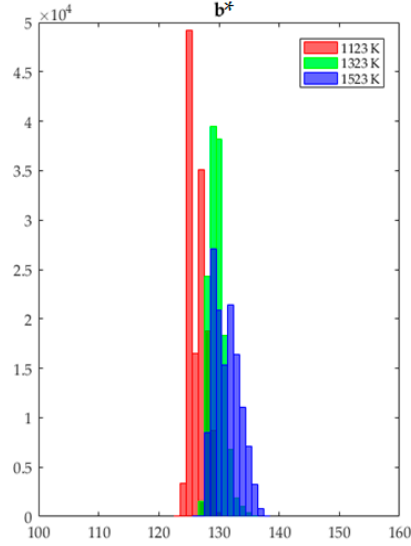

(c)

Figure 7. Blade surface image histograms from Figure 6 for individual heating temperatures, i.e., 1123 $\mathrm{K}, 1323 \mathrm{~K}$, and $1523 \mathrm{~K}$, components: (a) $\mathrm{L}^{*}$; (b) $\mathrm{a}^{*}$; (c) $\mathrm{b}^{*}$.

The diversification of the value present on the blade surfaces for individual heating temperatures is well shown by the spatial graph (example-component $b^{*}$ ) presented in Figure 8 . Based on the figure, it is possible to conclude that a selection of even one component may constitute important diagnostic information characterizing a blade surface for a defined heating temperature.

On the basis of the determined parameters (Section 2.2) supported by statistical analysis, a coherent representation of the features characterizing individual surfaces for different heating temperatures was obtained. They can be used to show a correlation between heating temperature (blade technical condition) and surface colour. Additionally, the Delta E parameter was used to determine the nature of colour value changes (differences) for individual surfaces representing different heating temperatures [29]. Due to a relatively uniform colour structure of the surface (low standard deviation value) characterizing each blade, the colour for individual heating temperatures was described with an average determined for the individual component representing the blade surface. The value of the Delta E parameter was determined as a Euclidean distance between two points in a 3D space (square root of the sum of squares of differences in each of the three coordinates, $\left.L^{*}, a^{*}, b^{*}\right)$ between a blade heated at $1123 \mathrm{~K}$ and blades heated at $1132 \mathrm{~K}$ and $1523 \mathrm{~K}$. The obtained results (distances of their mutual position in space) indicate also large differences between the surface colours for individual heating temperatures. 


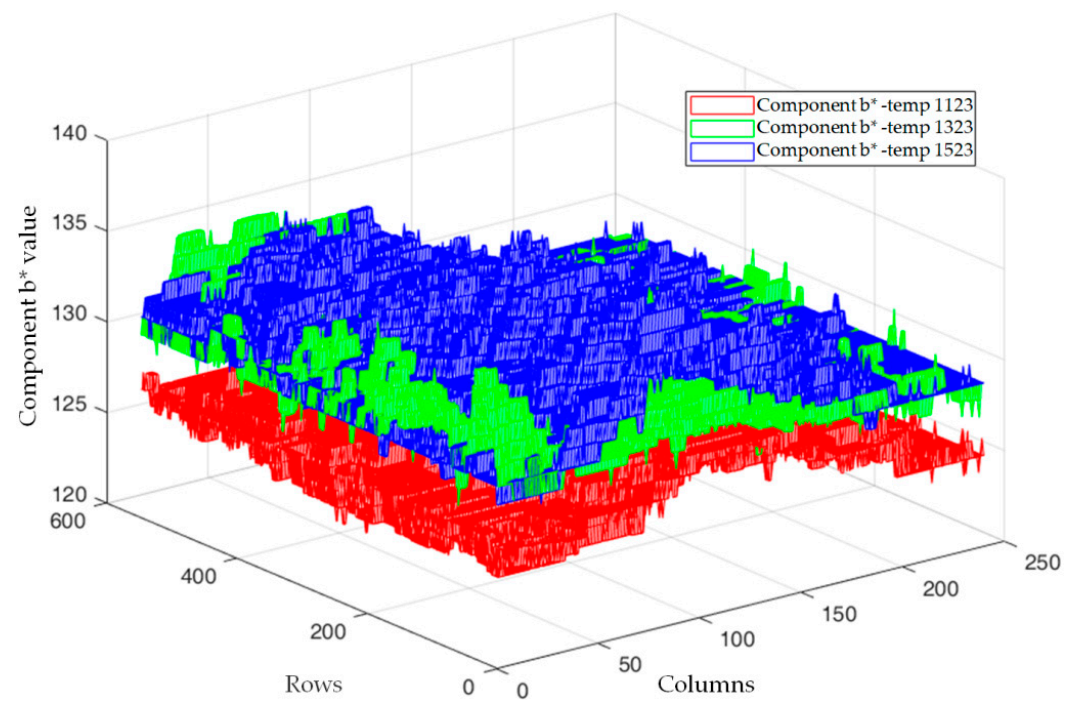

Figure 8. An example of differences present in the value distribution for component $b^{*}$.

\subsection{Thermographic Method and Test Results}

Heated blades were used in the first stage of thermographic examination. The "Echo Therm" system, which is equipped with a high-quality FLIR thermal imaging camera with a resolution of $320 \times 256$ pixels, two xenon lamps, and software supporting data capture and plotting temperature changes, was used for this purpose. The two Xenon lamps together generated $5 \mathrm{~kJ}$ of heat energy. For the tested surface to be homogeneous in terms of emissivity, it was covered with graphite. The high emissivity of graphite (0.86) is conducive to increasing the sensitivity of the temperature measurement method. Thus, prepared surfaces of the blades were at the same time and homogeneously excited by a thermal impulse. It should also be noted that all examined blades came from one series and were created in the same technological process. Before, the tests the blades were cleaned of sediments and then tested in pulsed thermography. Thermal images were recorded at $383 \mathrm{~Hz}$ (camera parameters: Thermal sensitivity $20 \mathrm{mK}$, detector InSb, wavelength 1.5-5.5 $\mu \mathrm{m}$ ). During the conducted blade tests, a point temperature measurement was made (averaged from $5 \times 5$ pixels) in three identical places. At this point, a change of temperature, $\mathrm{T}$, at a tested point was related to the initial temperature, $\mathrm{T}_{0}$. As a result of the test, a difference in the thermo-physical response of tested blades after heating at various temperatures was identified (Figure 9). It particularly applies to blades heated at a temperature of $1523 \mathrm{~K}$.

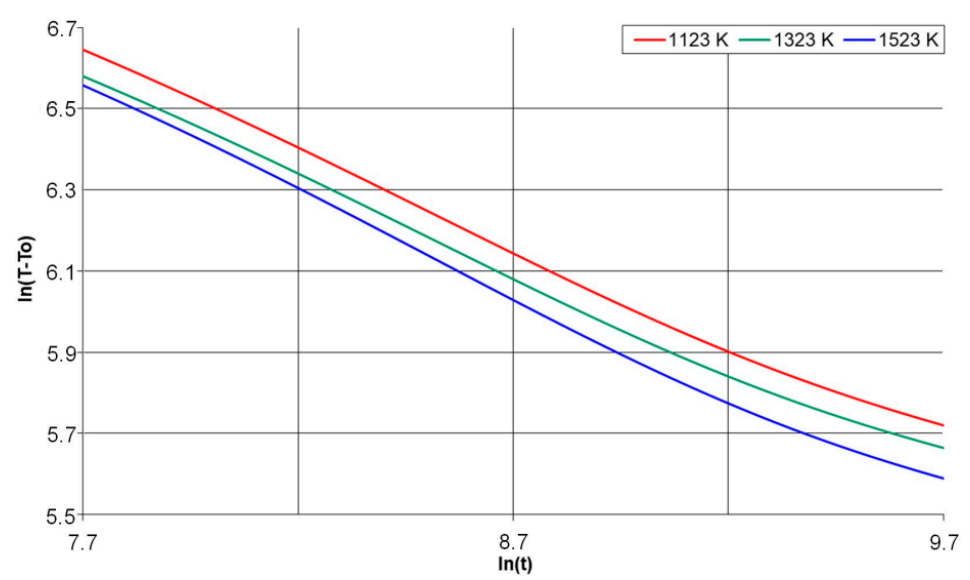

Figure 9. Average results of heat pulse response of the blade material heated for $2 \mathrm{~h}$ at different temperatures in the selected range, $\ln (\mathrm{t})=7.7-9.7$. 
To determine the ability to assess the condition of operated gas turbine blades with the thermographic method, blades in various technical conditions and classified with the optoelectronic method were tested. They were classified according to the following categories: New (bright colour), operated-fit (grey colour), and operated-overheated unfit (black colour). The "Echo Term" system with two xenon lamps was used once again and they were subjected to the impact of $4.5 \mathrm{~kJ}$ of thermal energy. The software implemented in the "Echo Term" system, supporting the interception of data and graphing of changes, was used. Based on the tests, changes in the relationships between thermal response parameters of the tested blades to a stimulating thermal pulse were shown (Figure 10).
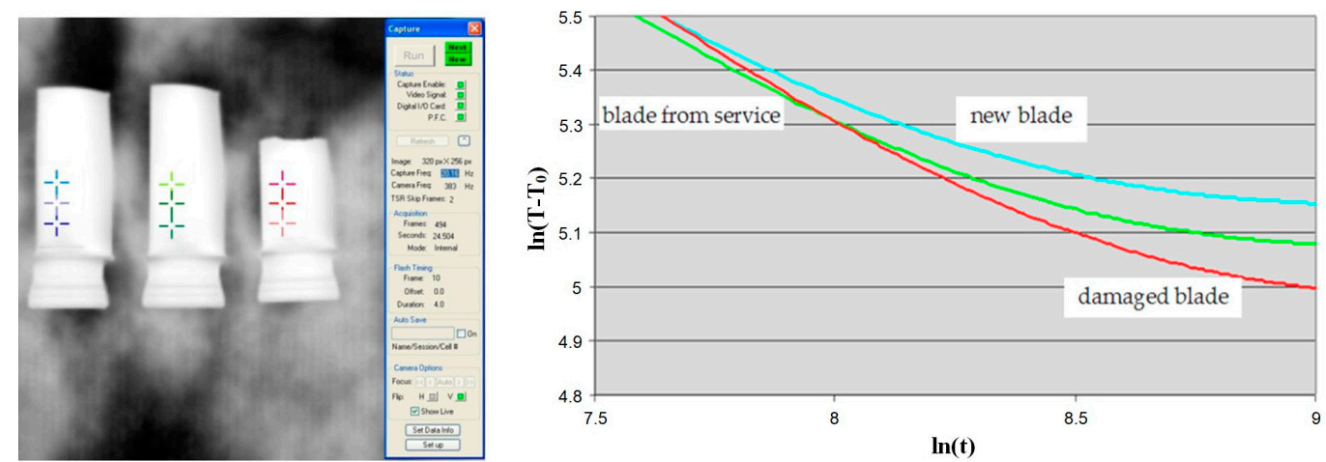

Figure 10. Average results of heat pulse material response for new and operated blades in the selected range, $\ln (\mathrm{t})=7.5-9$.

Every point in the infrared (IR) camera image represents a temperature-time data sequence for a point on the sample surface. According to theory, surface temperature falls by $1 / \sqrt{ } \mathrm{t}$ for an infinitely thick sample. In the case of the measurements shown in Figures 9 and 10, the measuring places (averaged from the $5 \times 5$ area) were established at places with an almost identical blade thickness lying on the leading edge. Figures 9 and 10 show only the selected range of blade material responses to heat excitation, showing the process of heat exchange with the environment. From the point of view of diagnostics, the presented ranges provide easy to interpret diagnostic information. In the case of heated blades, the initial temperature of the surface heated by the impulse was different for each of the blades (initial temperature is determined by thermal effusivity). Moreover, almost linear, non-overlapping waveforms (visible in Figure 9) indicate significant changes occurred in the material structure. The results presented in Figure 10 show that the damaged blade cooled faster, showing a greater ability to exchange thermal energy with the environment. Based on the analysis of the sequence of a thermal pulse response of the blade material heating for $2 \mathrm{~h}$ at different temperatures and material of operated blades, it can be noted that the nature of the rate of the heat abstraction changes was similar. In the case of heated blades (Figure 9), higher heat abstraction intensity was exhibited by a blade heated at a temperature of $1523 \mathrm{~K}$, whereas, in the case of operated blades (Figure 10), higher heat abstraction intensity was noticed among partially fit and overheated-unfit blades in comparison to new blades and blades heated at $1523 \mathrm{~K}$ (Figure 9). Taking into consideration the fact that after subjection to a heat pulse, the temperature distribution on the surface of the blades changes in time with the varying intensity for blades heated at various temperatures and operated blades being at varying states of usability (including damaged blades), this result is caused by changes that occurred in the structure of their material. This change in the structure of the blades' material causes the heat pulse to dissipate throughout the material at a varying intensity in respect to heated and operated blades (material overheating). The expansion and recrystallization of material grains causes an increase of thermal diffusion-Formula (2). Therefore, after thermal agitation, the temperature of the material of blades with larger and recrystallized grain reduces more intensively. 


\subsection{Blade Microstructure Tests}

Further actions involved metallographic tests of blades heated at different temperatures. The NIS-Elements AR/BR software as well as a Nikon microscope was used for the analysis of microstructural tests. The software is equipped with algorithms enabling the calculation of the content of individual precipitates/phases in an image recorded by the microscope, regardless of their shape. The results are expressed by a circle equivalent in diameter with the area equal to the grain surface.

Based on the analysis of microstructural heated blade tests (Figures 11-13), it was concluded that an increased average alloy grain size (Figure 11) and increasing particles of the alloy reinforcing phase $\gamma^{\prime}$ (Figure 12) were seen at a temperature of $1323 \mathrm{~K}$. Whereas, at a temperature of $1523 \mathrm{~K}$, there was significant growth of grain and, as a result of coagulation, the phase $\gamma^{\prime}$ particles with the greatest initial sizes grew (Figure 13). Therefore, a temperature of $1323 \mathrm{~K}$ favours the growth of phase $\gamma^{\prime}$ particles. Moreover, it can be concluded that increasing the test temperature causes a decrease in the number of $\gamma^{\prime}$ particles with the largest sizes relative to the microstructural condition of a blade material exposed to a temperature of $1123 \mathrm{~K}$. At the same time, a greater distance between phase $\gamma^{\prime}$ was noticed. The observed grain growth, and the linking and rippling of phase $\gamma^{\prime}$ particles significantly impacts the decline in the alloy creep resistance [1,19-22]. Based on the obtained results of microstructural tests, the noticeable impact of temperature on the strength of blades can already be observed after exposure to a temperature of $1323 \mathrm{~K}$. The blades' surface colour changed after heating. Significant difference occurred especially between heating temperatures of $1223 \mathrm{~K}$ and $1323 \mathrm{~K}$. The colour of the blades after being heated to temperatures of $1123 \mathrm{~K}$ and $1223 \mathrm{~K}$ was similar (the blades were dark brown-gray). However, at temperatures of $1323 \mathrm{~K}, 1423 \mathrm{~K}$, and $1523 \mathrm{~K}$, the surfaces were lighter in colour (Figure 4).

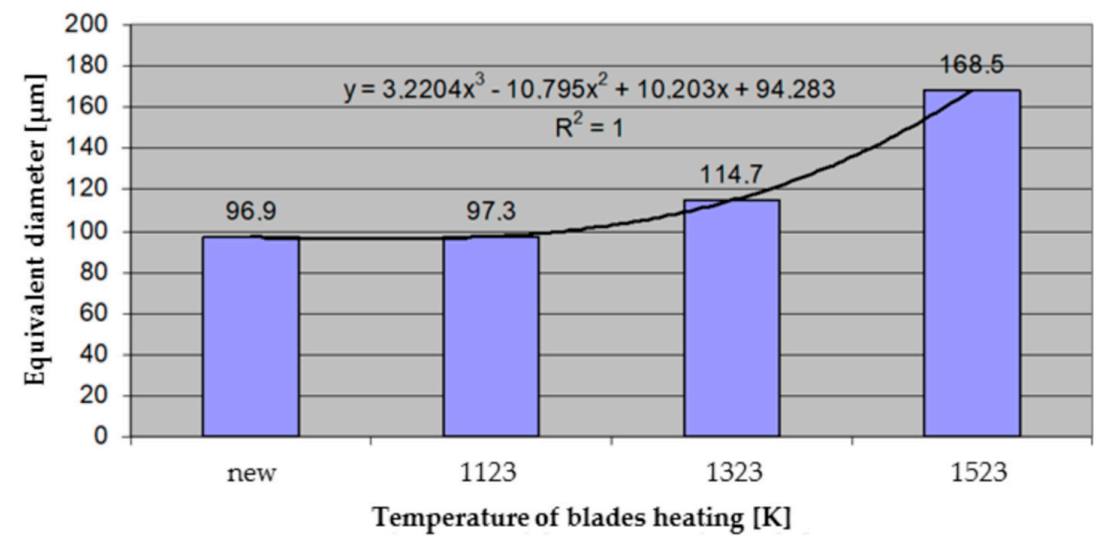

Figure 11. Change of an average grain size of blade alloy-new and heated at different temperatures for $2 \mathrm{~h}$-expressed by an equivalent diameter of a circle with an area equal to the grain surface area.

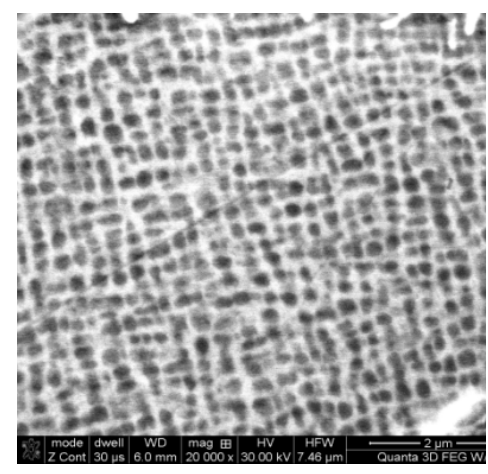

(a)

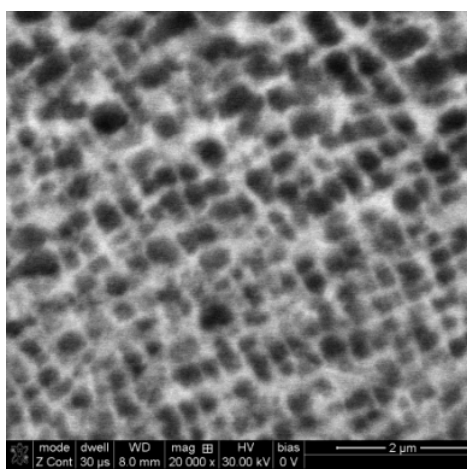

(b)

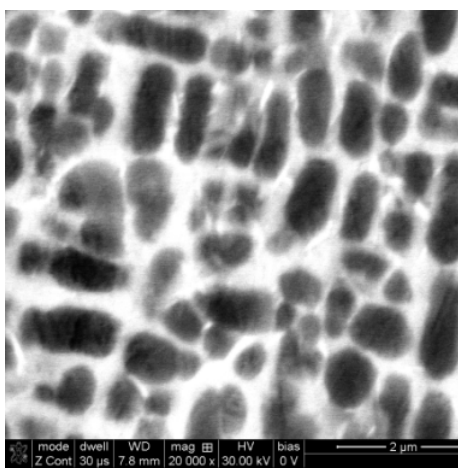

(c)

Figure 12. Microstructure of blades heated for $2 \mathrm{~h}$ at a temperature of: (a) $1123 \mathrm{~K}$, (b) $1323 \mathrm{~K}$, and (c) $1523 \mathrm{~K}$ (magn. $\times 20,000$ ) — coagulation, changed shape, and rippling of phase $\gamma^{\prime}$ precipitates are visible. 


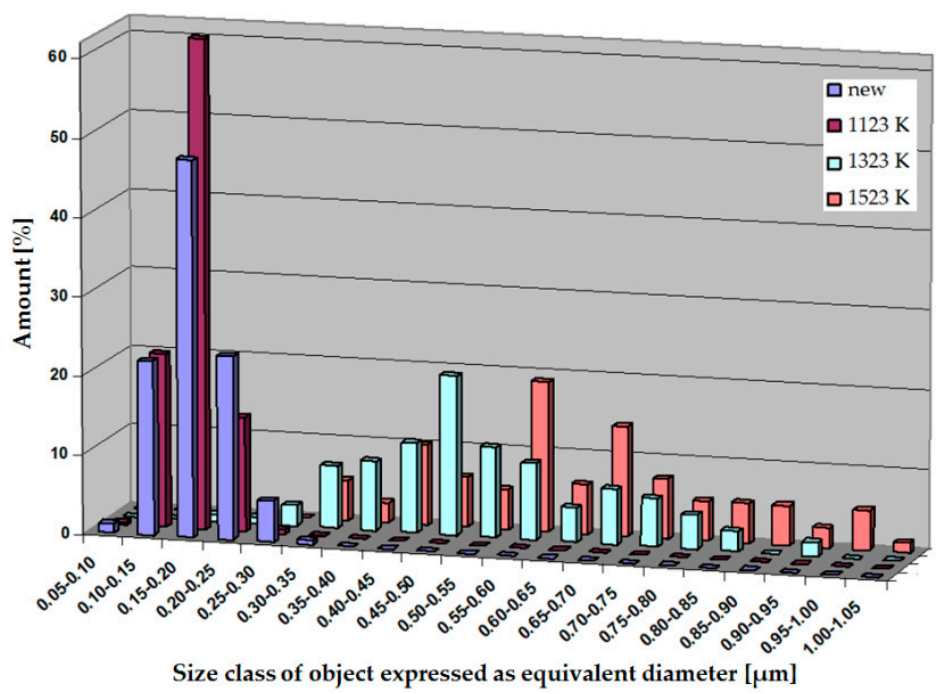

Figure 13. Number of precipitates of individual phase $\gamma^{\prime}$ particle size classes in the material of the blade-new and heated at $1123 \mathrm{~K}, 1323 \mathrm{~K}$, and $1523 \mathrm{~K}$.

The conducted metallographic examinations of blades heated at various temperatures demonstrated that a high temperature causes changes in EI-867 WD alloy microstructures (Figure 4).

In respect to operated blades under actual operating conditions, these blades are subjected to mechanical and thermal loads. The essence of low-cycle loads is the total and simultaneous destructive impact of variable high-amplitude mechanical and thermal loads. As a result of the conducted tests involving operated blades, similar to the case of heated blades, it can be concluded that under the impact of elevated temperature, the chemical composition, morphology, and the distribution of reinforcing phase $\gamma^{\prime}$ in the material structure changed adversely. In the case of operated blades, the morphology of phase $\gamma^{\prime}$ particles depended on the mechanical stress mark. Tensile stress, occurring along a blade axis during the rotation of a turbine rotor, supports the expansion of phase $\gamma^{\prime}$ on a plane perpendicular to the strain direction. As a result, the original cuboid shape changes into tiles whose wider walls are positioned perpendicular to the stress direction and the narrow walls are perpendicular to other cube directions. These adverse microstructural changes of the alloy exert a decisive impact on its strength properties. As in the case of heated blades, the growth of phase $\gamma^{\prime}$ led to precipitates' coagulation, hence, an adverse change of its shape. Moreover, the percentile share of phase $\gamma^{\prime}$ in the structure decreased. The change in the microstructure of operated blades, which depends on the time of blade exploitation within the engine as well as the temperature and time of its influence during the operation of the engine (Figure 10), occurred in a similar manner. As a result, the heat-resistance and heat-strength of the superalloy decreased.

\subsection{Discussion of the Test Results}

Based on the results of optoelectronic and thermographic tests of heated blades, it has been concluded that an alloy with a bigger grain size (Figure 11) and larger particles of the reinforcing phase $\gamma^{\prime}$ (Figures 12 and 13) generally displays increased thermal conductivity (Figure 9 for $\mathrm{T}=1523 \mathrm{~K}$ ). Increasing thermal conductivity comes with increasing thermal diffusivity expressed by Formula (2). It is thermal diffusivity that significantly impacts the blade temperature equalization rate. The greater the diffusivity, the faster the effects of thermal disturbance fade. Changes of specific density and heat do not significantly depend on the microstructural condition of a blade. Based on the results of the research of the operated blades with the use of the thermographic method (Figure 10), it can be stated that the intensity of equalizing temperatures of the blades correlated with their technical condition. The method of temperature equalization was similar to that for heated blades. The differences in the rate of temperature changes were, however, greater. During the process of exploiting the blade, the 
time of exposure to over-permissible flue gas temperature downstream of the turbine and its value are usually unknown. Based on the appearance of an operated blade and the results of metallographic tests, it can be concluded that in a partially fit blade, there was a significant increase of the grain size and phase $\gamma^{\prime}$ particles. This growth was particularly large in an unfit-overheated blade, which, due to lack of alloy strength, broke off during rotation $[12,14]$. Such a conclusion results from the greater intensity in temperature equalization of operated blades after a thermal pulse $[7,8,17]$.

Based on the association of a thermal response of the tested turbine element with the microstructural condition of a group of blades classified as new, operated, and overheated, a relationship was developed, which enables inferring in terms of the nature of changes (modifications) of the $\gamma^{\prime}$ phase, based on the obtained thermal response (Figure 14). The $\ln \left(T-T_{0}\right)$ parameter relationship chart in the function of the phase $\gamma^{\prime}$ size presents a criterion for evaluating a blade as fit or unfit. An object's thermal response to input $\ln \left(T-T_{0}\right)$ for $\ln (t)=9$, acquired by measuring instruments, determines the blade's material microstructure description (phase $\gamma^{\prime}$ precipitate size). A blade qualified as fit for further operation is a blade with the size of the $\gamma^{\prime}$ phase in its microstructure not exceeding $0.56 \mu \mathrm{m}$, whereas a blade unfit for further operation is characterized by an average number of phase $\gamma^{\prime}$ precipitates with a value equal to or higher than $0.56 \mu \mathrm{m}$. Hence, the results of thermographic tests provide information on the strength (alloy creep resistance), which is the fitness of the blade for further operation.

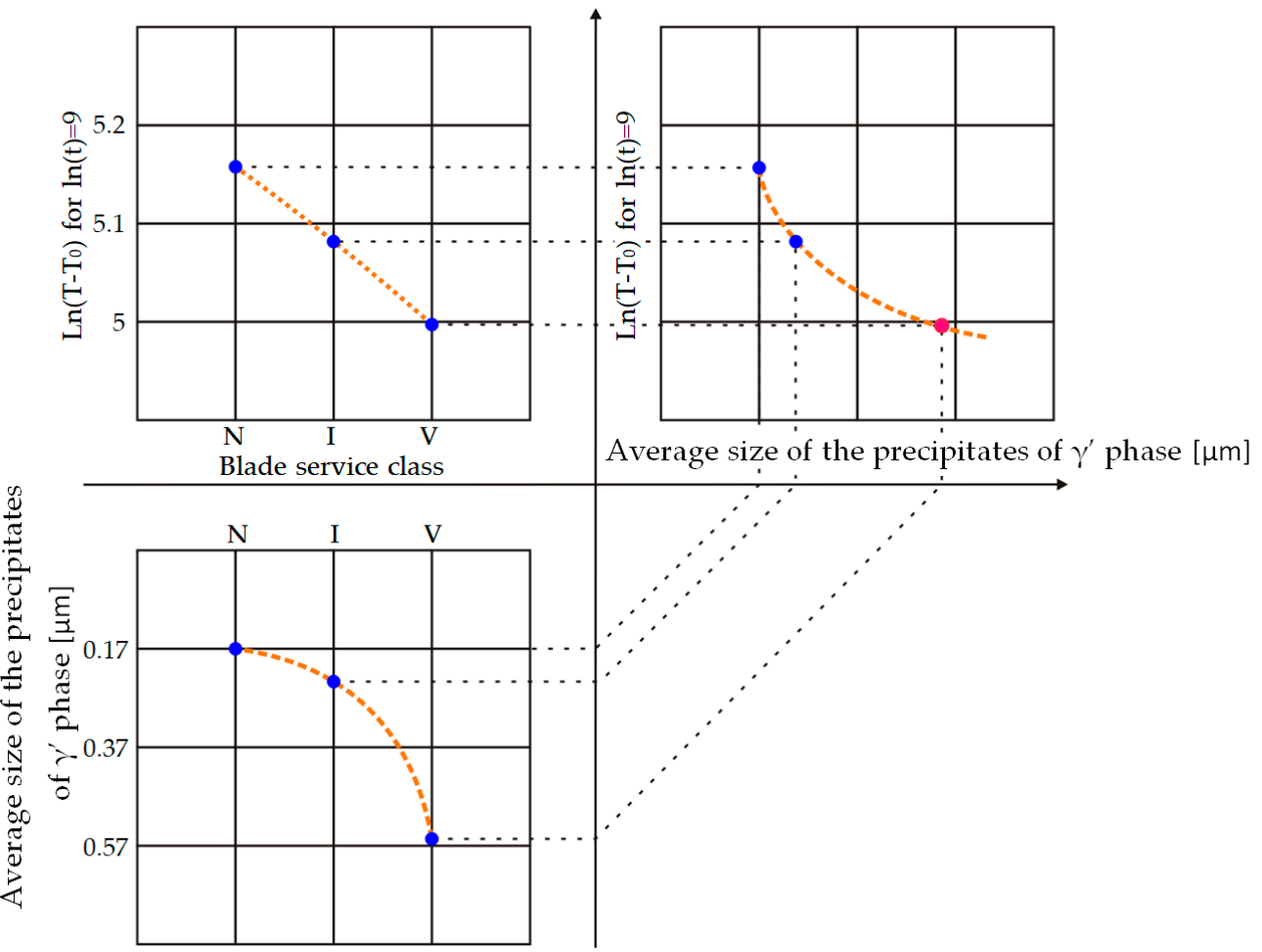

Figure 14. Example of dependence of the thermal response of EI-867WD alloy in the form of $\ln \left(T-\mathrm{T}_{0}\right)$ as a function of the average size of the $\gamma^{\prime}$ phase (expressed by an equivalent diameter). Blades: $\mathrm{N}-$ new, I-operated serviceable, $\mathrm{V}$-operated unserviceable.

\section{Conclusions}

A blade surface may be recorded with a light-sensitive detector thanks to a secondary light source reflected by its surface (visible range). Showing the relationship between the surface colour changes, correlated indirectly with blade material microstructure changes, provides information about a blade's technical condition. Nevertheless, operated blades are characterized by a more varied surface colour than in the case of the surfaces of heated blades. This results in an increased complexity of an approach 
towards images recorded in the visible light range and requires consideration of a larger number of factors and blade operating conditions. The suggested approach towards non-invasive evaluation of a blade's condition based on the observations of an object in various electromagnetic wave ranges (visible range, infrared) may provide new possibilities for diagnosing the technical condition of a tested turbine element. The image recorded using thermographic measuring-recording instruments was the thermal response of a turbine element excited with a short thermal pulse. The reaction of the blade's material to a thermal pulse enables inferences regarding its microstructural decohesion and, hence, about the strength of a blade and its further ability to be used. Accepting microstructural changes as a strength criterion, it was possible to determine the threshold value of a blade's fitness.

The realized studies show the possibility of assessing changes in the microstructure of blades, both using the optoelectronic method as well as the thermographic method, of uncooled turbines, which are especially vulnerable to this type of damage. The attempt to develop the foundations of a non-destructive methodology for the assessment of the usability of the blades of an aeronautical gas engine turbine with the use of optoelectronic and thermographic methods shows the innovative character of the present article.

Author Contributions: Conceptualization M.B. and J.B.; Methodology M.B. and J.B.; Software M.B and M.D.; Validation M.B. and J.B.; Formal Analysis M.B. and M.D.; Investigation M.B. and A.K.; Data Curation M.B. and A.K.; Writing-Original Draft Preparation M.B and J.B.; Writing-Review \& Editing M.B. and J.B.

Funding: This work was financed by Ministry of Science and Higher Education of Poland within the frame of projects (no. 6215 Air Force Institute of Technology).

Conflicts of Interest: The authors declare no conflict of interest. The founding sponsors had no role in the design of the study; in the collection, analyses, or interpretation of data; in the writing of the manuscript and in the decision to publish the results.

\section{References}

1. Sims, C.T.; Stoloff, N.S.; Hagel, W.C. Superalloys II-High-Temperature Materials for Aerospace and Industrial Applications; John Wiley \& Sons: New York, NY, USA, 1987.

2. El-Sayed, A.F. Performance Parameters of Jet Engines. In Aircraft Propulsion and Gas Turbine Engines; CRC Press: Bocaton, FL, USA, 2008; ISBN 9780849391965.

3. Carter, T.J. Common failures in gas turbine blades. Eng. Fail. Anal. 2005, 12, 237-247. [CrossRef]

4. Soares, C. Gas Turbines: A Handbook of Air, Land and Sea Applications, 2nd ed.; Elselvier: Oxford, UK, 2014; ISBN 9780124104853.

5. Pollock, T.M.; Tin, S. Nickel-based superalloys for advanced turbine engines: Chemistry, microstructure and properties. J. Propuls. Power 2006, 22, 361-374. [CrossRef]

6. Matzkanin, G.A. Selecting a nondestructive testing method, Part II: Visual inspection. AMMTIAC Q. 2007, 1, 7-10.

7. Korczewski, Z. Operational causes of fatigue failures within passages of gas turbine engines. Pol. Marit. Res. 2010, 17, 57-61. [CrossRef]

8. Artamonov, V.V.; Artamonov, V.P. Diagnostics of the causes of the operational destruction of rotor blades of gas turbines. Russ. J. Nondestruct. 2013, 49, 538-542. [CrossRef]

9. Kim, S.G.; Hwang, Y.H.; Kim, T.G.; Shu, C.M. Failure analysis of J85 Engine turbine blades. Eng. Fail. Anal. 2008, 15, 394-400. [CrossRef]

10. Reed, R.C. The physical metallurgy of nickel and its alloys. In The Superalloys Fundamentals and Applications; Cambridge University Press: Cambridge, UK, 2006; pp. 33-114. ISBN 9780511541285.

11. Sujata, M.; Madan, M.; Raghavendra, K.; Venkataswamy, M.A.; Bhaumik, S.K. Identification of failure mechanisms in nickel base superalloy turbine blades through microstructural study. Eng. Fail. Anal. 2010, 17, 1436-1446. [CrossRef]

12. Błachnio, J.; Bogdan, M.; Zasada, D. Increased temperature impact on durability of gas turbine blades. Eksploat. Niezawodn. 2017, 19, 48-53. [CrossRef]

13. Błachnio, J.; Bogdan, M. A non-destructive method to assess condition of gas turbine blades based on the analysis of blade surface image. Russ. J. Nondestruct. 2010, 46, 860-866. [CrossRef] 
14. Błachnio, J.; Bogdan, M.; Kułaszka, A. New non-destructive methods of diagnosing health of gas turbine blades. In Advances in Gas Turbine Technology; Benini, E., Ed.; InTech: London, UK, 2011; pp. 465-498, ISBN 9789533076119.

15. Carl, V.; Becker, E.; Sperling, A. Thermography inspection system for gas turbine blades. In Proceedings of the 7th European Conference on non-destructive testing, Copenhagen, Denmark, 26-29 May 1998; pp. 2658-2665.

16. Marinetti, S.; Robba, D.; Cernuschi, F.; Bison, P.G.; Grinzato, E. Thermographic inspection of TBC coated gas turbine blades: Discrimination between coating over-thicknesses and adhesion defects. Infrared Phys. Technol. 2007, 49, 281-285. [CrossRef]

17. Kułaszka, A.; Błachnio, J. Analysis of applicability of thermography to assess health of gas turbine blades. J. KONES 2013, 20, 237-244.

18. Ptaszek, G.; Cawley, P.; Almond, D.; Pickering, S. Transient thermography testing of unpainted thermal barrier coating (TBC) systems. NDT E Int. 2013, 59, 48-56. [CrossRef]

19. Tajra, S.; Otani, R. The Theory of High-Temperature Strength of Materials; Mietałurgija: Moscow, Soviet Union, 1986. (In Russian)

20. Poznańska, A. Lifetime of Aircraft Engine Blades Made of EI-867 Alloy upon Aspect of Non-Uniform Distortion and Structural Changes. Ph D. Thesis, University of Technology in Rzeszów, Rzeszów, Poland, 2000. (In Polish)

21. Sieniawski, J. Criteria and Methods of Evaluation of Materials for Elements of Aircraft Turbine Engines; Technical University Rzeszów: Rzeszów, Poland, 1995. (In Polish)

22. Salam, I.; Tauqir, A.; Khan, A.Q. Creep-fatigue failure of an aero engine turbine blades. Eng. Fail. Anal. 2002, 9, 335-347. [CrossRef]

23. Silveira, E.; Atxaga, G.; Erauzkin, E.; Irisarri, A.M. Study on the root causes for the premature failure of an aircraft turbine blade. Eng. Fail. Anal. 2009, 16, 639-647. [CrossRef]

24. Gevers, T.; Gijsenij, A.; Weijer, J.; Geusebroek, J.M. Color in Computer Vision: Fundamentals and Applications; Wiley: Hoboken, NJ, USA, 2012.

25. Koschan, A.; Abidi, M.A. Digital Color Image Processing; Wiley-Interscience: New York, NY, USA, 2008; ISBN 9780470147085.

26. Pass, G.; Zabih, R.; Miller, J. Comparing Images Using Color Coherence Vectors. In Proceedings of the ACM International Multimedia Conference \& Exhibition, San Jose, CA, USA, 6-10 February 1997.

27. Brunelli, R.; Mich, O. Histograms Analysis for Image Retrieval. Pattern Recognit. 2001, 34, $1625-1637$. [CrossRef]

28. Kodituwakku, S.R.; Selvarajah, S. Comparison of Color Features for Image Retrieval. Ind. J. Comput. Sci. Eng. 2004, 1, 207-211.

29. Sharma, G. Color fundamentals for digital imaging. In Digital Color Imaging Handbook; Sharma, G., Bala, R., Eds.; CRC Press, Taylor and Francis Group: Boca Raton, FL, USA, 2003; ISBN 139781420041484.

30. Maldague, X.P. Theory and Practice of Infrared Thermography for Non-Destructive Testing; Willey-Interscience: New York, NY, USA, 2001.

31. Oliferuk, W. Infrared Thermography for Non-Destructive Testing of Materials and Equipment; Gamma Office: Warsaw, Poland, 2008. (In Polish)

32. Bagavathiappan, S.; Lahiri, B.B.; Saravanan, T.; Philip, J.; Jayakumar, T. Infrared thermography for condition monitoring-A review. Infrared Phys. Technol. 2013, 60, 35-55. [CrossRef]

33. Czichos, H. Handbook of Technical Diagnostics: Fundamentals and Application to Structures and Systems; Springer Science \& Business Media: Berlin, Germany, 2013.

34. Yang, L.Y.; Zhu, Z.W.; Ming, J.T.; Zhang, A.B.; Zhang, W. Investigation on the damage evolution in the impacted composite material based on active infrared thermography. NDT E Int. 2016, 83, 114-122.

35. Gao, C.; Meeker, W.Q.; Mayton, D. Detecting cracks in aircraft engine fan blades using vibrothermography nondestructive evaluation. Reliabil. Eng. Syst. Saf. 2014, 131, 229-235. [CrossRef]

36. Tang, Q.; Dai, J.; Bu, C.; Qi, L.; Li, D. Experimental study on debonding defects detection in thermal barrier coating structure using infrared lock-in thermographic technique. Appl. Therm. Eng. 2016, 107, 463-468. [CrossRef]

37. Shepard, S.M.; Lhota, J.R.; Rubadeux, B.A.; Wang, D.; Ahmed, T. Reconstruction and enhancement of active thermographic image sequences. Opt. Eng. 2003, 42, 1337-1342. [CrossRef] 
38. Goldammer, M. Active Thermography for Dimensional Measurements on Gas Turbine Components. In Proceedings of the European Conference of non-destructive Testing ECNDT, Berlin, Germany, 25-29 September 2006.

39. Yang, R.; He, Y. Optically and non-optically excited thermography for composites: A review. Infrared. Phys. Technol. 2016, 75, 26-50. [CrossRef]

40. Bejan, A.; Krauss, A.D. Heat Transfer Handbook; John Willey \& Sons: Hoboken, NJ, USA, 2003. 